\title{
Disaster Medicine
}

and Public Health Preparedness

圈圈期 CAMBRIDERSITY PRESS

Medical emergencies requiring first aid at home: A population-based survey study.

\begin{tabular}{|c|c|}
\hline Journal: & Disaster Medicine and Public Health Preparedness \\
\hline Manuscript ID & DMPHP-20-1848.R1 \\
\hline Manuscript Type: & Original Research \\
\hline $\begin{array}{r}\text { Date Submitted by the } \\
\text { Author: }\end{array}$ & 08-May-2020 \\
\hline Complete List of Authors: & $\begin{array}{l}\text { Alhasan, Dalal; Public Authority for Applied Education and Training, } \\
\text { Monger, Eloise; University of Southampton, Department of Critical care } \\
\text { nursing } \\
\text { Brightwell, Richard; Edith Cowan University, School of Medical and } \\
\text { Health Sciences }\end{array}$ \\
\hline Keywords: & First aid, Accident, Functional outcome, Burden, Kuwait \\
\hline Abstract: & $\begin{array}{l}\text { Background: The objective of this study is to describe medical } \\
\text { emergencies occurring at people's homes requiring first aid; } \\
\text { characteristics, burden and impact on functional outcome. Method; a } \\
\text { confidential, cross-sectional survey, primarily based on } 2015 \text { American } \\
\text { Heart Association and American Red Cross first aid guidelines, was } \\
\text { conducted among adults ( }>18 \text { years) from } 12 \text { education centers, } \\
\text { Ministry of Awqaf and Islamic affairs, state of Kuwait. Results: A total of } \\
3000 \text { self-administered questionnaires were distributed between } 16 \\
\text { September-30 November } 2019 \text {. Medical emergencies prevalence } 118.5 \\
\text { per } 100,000 / \text { year. Women were more likely to encountered medical } \\
\text { emergencies } 78 \%(n=238) \text {.Victims above } 18 \text { years of age were more } \\
\text { likely to experience hypoglycemia } 39 \%(n=55), \text { while children suffered } \\
\text { from hypoglycemia } 19 \%(n=22) \text { or burns } 17 \%(n=20) \text {. Compliance with } \\
\text { first aid guidelines was seen in, hypoglycemia } 31 \%(n=44) \text { but lacking } \\
\text { during burns incidents } 44 \%(n=15) \text {.participants called the ambulance } \\
\text { only in seizures } 50 \%(n=13), 62 \% \text { of medical emergencies required } \\
\text { attendance at a healthcare facility and } 29 \% \text { required hospital admission. } \\
15 \% \text { of victims missed school or day of work and } 25 \% \text { had impaired } \\
\text { functional outcome. Conclusion: Home medical emergencies are } \\
\text { relatively common in Kuwait. Public training on first aid is low. Kuwait } \\
\text { has unique medical emergencies. Hypoglycaemia, seizure and burns are } \\
\text { the most frequent medical emergencies at home. Medical emergencies } \\
\text { are causing a burden on healthcare system. Quarter of medical } \\
\text { emergencies had negative impact on victim's functional outcome. }\end{array}$ \\
\hline
\end{tabular}




\section{SCHOLARONE ${ }^{m}$ \\ Manuscripts}

Cambridge University Press 
Title: Medical emergencies requiring first aid at home: A population-based survey study.

Authors:

Dalal Al Hasan, MD, MS, PhD ${ }^{1}$ (dm.alhasan@paaet.edu.kw)

Eloise Monger, $\mathrm{PhD}^{2}$ (E.monger@soton.ac.uk)

Richard Brightwell, MS, $\mathrm{PhD}^{3}$ (r.brightwell@ecu.edu.au)

${ }^{1}$ Department of Applied Medical Sciences, Health Sciences College, Public Authority of Applied Education and training, State of Kuwait

${ }^{2}$ Department of Critical care nursing, University of Southampton, Southampton, United Kingdom

${ }^{3}$ School of Medical and Health Sciences, Edith Cowan University, Perth, Australia

\section{Corresponding Author/Reprints:}

Dalal Al Hasan, MD, MS, PhD

Assistant Professor of Emergency Medical services

Department of Applied Medical Sciences

Health Sciences College

Public Authority of Applied Education and training

State of Kuwait

Tel: +965 97964699

Email:dm.alhasan@paaet.edu.kw

Running Head: First aid related incidents impact on functional outcome.

Word Count: 2,425 words

Keywords: First aid, functional outcome, accident, Kuwait.

Acknowledgement: The authors would like to acknowledge and thank Dr Janvier Gasana for his enormous help and support rendered in the course of structuring the data collection tool for the study. 
The authors report no conflicts of interest. The authors are responsible for the content and writing of the paper.

The authors report that no funding was required for this research.

\section{Authors' contributions:}

Study conception and design: DA.

Acquisition of data: DA

Analysis and interpretation of data: DA

Drafting of manuscript: RB,EM.

Critical revision: RB,EM.

All authors read and approved the final manuscript 
1 Abstract

2 Background: Most medical emergencies requiring first-aid occur at home. Little is known 3 about the prevalence of specific medical emergencies at home requiring first aid. The objective 4 of this study is to describe medical emergencies occurring at people's homes requiring first 5 aid; characteristics, burden and impact on functional outcome and to address the national 6 public knowledge and practices of first aid. Method; a confidential, cross-sectional survey 7 ,primarily based on 2015 American Heart Association (AHA) and American Red Cross first 8 aid guidelines, was conducted among adults (>18 years) from 12 educational centers, Ministry 9 of Awqaf and Islamic affairs, state of Kuwait. Results: A total of 3000 self-administered 10 questionnaires were distributed between 16 September-30 November 2019. The response rate 11 was $34 \%(n=1033$ participants $)$ and $1 \%(n=11)$ were partially answered questionnaires 12 leaving 1022 questionnaires for valid statistical analysis. The prevalence of medical 13 emergencies 118.5 per 100,000/ year. Level of public knowledge19\%. Medical emergencies 14 were more likely to occur in Hawali province $49 \%(n=149)$, women were more likely to 15 encountered medical emergencies $78 \%(n=238)$.Victims above 18 years of age were more likely 16 to experience hypoglycemia $39 \%(n=55)$ and children were more likely to suffer from 17 hypoglycemia $19 \%(\mathrm{n}=22)$ or burns $17 \%(\mathrm{n}=20)$. Compliance with first aid guidelines was seen 18 in, hypoglycemia $31 \%(n=44)$ but lacking in burn incidents $44 \%(n=15)$.participants called the 19 ambulance in seizures $50 \%(n=13), 62 \%$ of medical emergencies required attendance at a 20 healthcare facility and $29 \%$ required hospital admission. $15 \%$ of victims missed school or day 21 of work and $25 \%$ had impaired functional outcome. Conclusion: Home medical emergencies 22 are relatively common in Kuwait. Public training on first aid is low. Kuwait has unique medical 23 emergencies. Hypoglycaemia, seizure and burns are the most frequent medical emergencies at 24 home. Medical emergencies are causing a burden on healthcare system. Quarter of medical 25 emergencies had negative impact on victim's functional outcome. 
27 First aid is defined as the helping behaviour and initial care provided for an acute illness or 28 injury $^{[1]}$. Indeed, it is the provision of initial care for an illness or injury, usually by a non29 expert but trained person, until medical treatment can be accessed ${ }^{[2]}$. Provision of immediate 30 first aid to patients who require emergency care can make a significant difference to the 31 outcome ${ }^{[3]}$, as the first action taken for management of injuries and common illness decides 32 the future course of disease and complication rates ${ }^{[4]}$. In certain self-limiting illnesses or minor 33 injuries, appropriate first aid measures may be sufficient to avoid a medical consultation ${ }^{[4]}$.

34 Most incidents requiring first-aid occur in places where people feel secure - at home in 35 particular ${ }^{[5]} .41 .4$ percent of accidents in the United Kingdom happen at home, whilst 19.5 36 percent are on roads ${ }^{[5]}$. Among children, injuries from home accidents actually constitute a 37 public health problem. According to the National Safe Kids Campaign in the United States $3840 \%$ of deaths and $50 \%$ of non-fatal unintentional injuries occur in and around the home ${ }^{[2]}$.

39 In Europe alone, visits to hospital Emergency Department (ED) following an incident in the 40 home reached 20.2 million a year ${ }^{[5]}$. First aid education and training not only save lives but 41 also reduces the severity of medical emergencies, the high cost of medical treatment and the 42 long-term consequences of severely injuries people ${ }^{[5]}$. And although first aid is not a 43 replacement of emergency medical services (EMS), it's a vital and effective initial 44 intervention. EMS systems response time in developed countries varies between 6-8 minutes 45 [6]. The local EMS systems mean response time $9.3 \pm 5$ minutes ${ }^{[7]}$. Potential life saving measures 46 for home incidents need to be delivered in a narrower time window by witnessing bystanders 47 [5-6].

48 The 2015 American Heart Association and American Red Cross Guidelines Update for first 49 aid divide emergency cases in to medical and trauma emergencies. Medical emergencies 50 include the following: shortness of breath, stroke, chest pain, anaphylaxis, hypoglycaemia, 51 seizure, cardiac arrest, syncope and poisoning while trauma emergencies include: obstructed 52 airway, bleeding, wounds, burns and spinal injury.

53 To date, Middle Eastern countries have limited studies on medical emergencies at home ${ }^{[8-10]}$.

54 Medical emergencies at home have not yet been reported in Kuwait. The objective of this 55 study is to describe medical emergencies occurring at people's homes; characteristics, burden 
56

57

\section{Method}

62 A qualitative descriptive approach was used to analyse the case studies. This approach was 63 used to develop an in-depth description and analysis of multiple cases. A confidential, cross64 sectional survey conducted among education centers, Ministry of Awqaf and Islamic affairs, 65 state of Kuwait ${ }^{[11]}$. The study targeted participants from 12 education centers across Kuwait's 66 six provinces: Al Asimah, Hawali, Al Farwanya, Al Jahra, Mubarak Al Kabeer and Al Ahmidi 67 [11].

71 There are 90 education centers across Kuwait's six provinces with 20,000 enrolled students 72 above the age of $18^{[11]}$. The education centers accept all adult applicants regardless to their age, 73 gender, nationality or background ${ }^{[11]}$. Their wide distribution all over Kuwait provinces and 74 their mixed culture in terms of age, professional background, nationalities and gender made 75 education centers' population representative of Kuwait population with its variable 76 demographics ${ }^{[12]}$.

77 The investigator approached the administration department of two education centers in each 78 province to disseminate a paper-based questionnaire about medical emergencies at home. The 79 administration departments then distributed the questionnaire to students via the teaching 80 staffs.

and impact on functional outcome and to address the national public knowledge and practices of first aid.

Study design and Setting:

To optimise representativeness of the population, teaching staff administered the questionnaire randomly to participants during the general required classes in which participants from all specialities are registered and allowed 15 minutes to complete the questionnaire. Participants completed a multiple-choice question on their medical emergencies at home occurring at their homes during the year of 2018. Therefore no reminder were used. 


\section{Study instruments and variables assessment:}

The questionnaire included 15 multiple choice questions with space for additional answers. The questionnaire categories included demographic characteristics of participants ( 5 items), general first aid knowledge ( 1 item), medical emergencies at home ( 3 items), medical emergencies practice (1 item), and medical emergencies burden ( 2 items), and medical emergencies impact ( 2 items). Aside from the participants demographic information, the questionnaire domains were primarily based on 2015 American Heart Association and American Red Cross first aid guidelines.

In the questionnaire, general first aid knowledge is assumed from the undertaking of first aid training. The occurrence of medical emergencies at home is a yes/no response, while the type of medical emergency is based on the 2015 American Heart Association and American Red Cross first aid list of emergencies. The initial practices at the time of medical emergency at home were again founded on 2015 American Heart Association's and American Red Cross' first aid recommendations. A participant who selected a response that is compliant with the AHA recommendation was categorised as " appropriate management, in-line with AHA recommendation". A participant who chose a response non-compliant with AHA recommendation was categorised as ' inappropriate management, not in-line with AHA recommendation'. In this item, we also included two responses; 'not doing anything' and 'calling the ambulance'. these responses were categorised as 'no action' in our analysis.

The burden of the medical emergencies was assessed by identifying whether a consultation at a health care facility occurred and whether a hospital admission was required.

The impact of medical emergencies on functional outcome was assessed by evaluating functional outcome after the incident occurrence and the length of period of recovery. This is because measures of functional outcome and general well-being are becoming increasingly important in evaluating strategies to reduce the burden of injury ${ }^{[13]}$. We define functional outcome as Which is defined as limitations in activities of daily living including toilet use, grooming, bathing, dressing, feeding and transfer ${ }^{[10]}$ and recovery period is the time required for a patient to return to his / her normal function.

The questionnaire was scrutinised by an expert, reviewer for refinement and re-wording of questions to ensure that statements were understandable and meaningful to the participants, The reviewer also ensured that there was face validity. Two review rounds were conducted

\section{Cambridge University Press}


121 before the questionnaire was concluded. Reliability of questionnaire items was examined using

122 SPSS split-half reliability index formula on 50 initial participants. Problematic items were removed once a correlation coefficient of $(r)>0.80$ was established.

125 Sample size

126 All participants were recruited from the identified education centers and were adults $(>18$ 127 years old) enrolled at the college between 15 September and 30 November 2019.

128 The calculated minimum target sample size was 385 (n) using Cochran's formula. This was 129 based on the Kuwait current population being 4,137,000 people ,setting a power of $95 \%$.

130 Random sampling was used to obtain the study population.

131

132 Statistical methods

133 All data were analyzed using SPSS (Version 23 for Windows) (SPSS Statistics for Windows, 134 Version 23.0. Armonk, NY: IBM Corp). Frequency distribution and descriptive criteria were 135 calculated. Questionnaire responses were compared using Chi-squared test .A $P<0.05$ was 136 considered to indicate statistical significance in all cases.

139 Ethical approval was granted approved by IRB committee on December 5 2019. Consent is 140 anticipated with completion of the questionnaire. Participant confidentiality is ensured as the 141 questionnaire forms were anonymous ${ }^{[14]}$.

142

143 Results

145 A total of 3000 self-administered questionnaires were distributed randomly among Kuwait six 146 provinces. The response rate was $34 \%(n=1033$ participants) and $1 \%(n=11)$ were partially 147 answered questionnaires leaving 1022 valid questionnaires for statistical analysis.

148 Of the 1022 participants, $30 \%(n=303)$ reported medical emergencies occurrence at their 149 homes, A prevalence of 118.5 per $100,000 /$ year .

150

151 Level of public knowledge 
$19 \%$ of participants had received previous first aid training. Women (53\%) and people with a non-health related background (49\%) were the most likely to have attended first aid training. Moreover, had the highest rates of trained lay people in Kuwait (35\%) followed by Al-Ahmadi province (22\%) and the lowest in Mubarak Al-Kabeer province (7\%). Having received previous training in First Aid doubled the lay persons chance of proving appropriate management in medical emergencies at home (Table 1).

Characteristics of medical emergencies

Medical emergencies were more likely to occur in Hawali province $49 \%(n=149)$. Females participants were more likely to report medical emergencies at their homes $78 \%(n=238)$ (Figure 1). Victims of medical emergencies had variable presentations. Victims above 18 years of age were more likely to experience hypoglycemia $39 \%(n=55)$. Whereas victims $1-8$ years of age group were more likely to suffer from hypoglycemia $19 \%(\mathrm{n}=22)$ or burns 17 $\%(n=20)$ (Figure 2). In terms of compliance with first aid guidelines during medical emergencies, hypoglycemia was the most appropritaely managed medical emergency $31 \%(n=44)$, whilst burns were the least appropriately managed incident $44 \%(n=15)$. Participants were more likely to call an ambulance without providing first aid during seizures $50 \%(n=13)$ (Figure 3$)$.

Impact and burden of medical emergencies at home

Overall $62 \%$ of medical emergencies required attendance at a healthcare facility and $29 \%$ required hospital admission, a prevalence of 117.4 per 100,000 a year. Incidents of hypoglycemia and seizures incidents were more likely to require a health care facility visit and hospital admission (Table 2).

In terms of impact on victims of medical emergencies, $15 \%$ missed school or day of work or school and $25 \%$ had impaired functional outcome (Table 3 ). 


\section{Discussion}

\section{Level of public knowledge}

The observed level of training among the public is within range of western countries $(95 \%$ $5 \%)^{[15]}$ but lower than regional countries, $33.8 \%^{[16]}$. This maybe because first aid training is voluntary in Kuwait.

Our analysis showed first aid training doubled participant's chance of providing appropriate management during medical emergencies. First aid programs are known to cause better help and higher helping rates $^{[17]}$.

Characteristics of medical emergencies

Our study reports unique characteristics of medical emergencies at home. Victim's age, medical emergency type were all new to the literature. In the United States, unintentional home incidents were more likely to occur among the over 75 years age group $\left.{ }^{[17}.\right]$ Poisoning and falls were the commonest underlying causes of those medical emergencies ${ }^{[17]}$.

There are also some discrepancies in participant's initial practices during medical emergencies at home. Our study participants appropriately managed hypoglycaemia but poorly managed burns. Inadequate first aid is common during burn's management ${ }^{[18-19]}$. Furthermore, no action was taken during seizure emergencies. Providing first aid for seizures appears to be a global challenge, O' Hara 2007 et al. documented low first aid provision during seizures in a group of school nurses, EMS personnel and teachers ${ }^{[20] .}$

Impact and burden of medical emergencies

Medical emergencies at home caused a burden on the health care system. $56 \%$ of medical emergencies required health care facility. To our knowledge, this is the first study to estimate victim's approach to health care facility after medical emergency ${ }^{[21-22]}$. The burden was again confirmed by high hospital admission rate.

More over medical emergencies at home had a negative impact on functional outcome and recovery time. These outcomes have never been addressed before in the literature.

\section{Cambridge University Press}


The main strengths of this study are the following: This is the first study that complies with the 2015 American Heart Association and Red Cross guidelines and recommendations during medical emergencies evaluation. Second, the proposed study is the first to evaluate home medical emergencies impact on functional outcome. Third, this research is one of few to address impact of first aid training of appropriate management during medical emergencies at home. on a national level, this is the first national study on medical emergencies at home of Kuwait.

\section{Limitations}

limitations of the study include; the nature of a self-administered survey which is based on recall making it open to bias. The current study maximized the optimum recall period, by asking respondents to record events with in the last 12 months. Another limitation is that although the sample size is appropriate to Kuwaiti population, other countries in the region are more heavily populated. Therefore the replication of this study in another setting can produce different results.

\section{Conclusion:}

Home medical emergencies are relatively common in Kuwait. Public training on first aid is low. Kuwait has unique medical emergencies. Hypoglycaemia, seizure and burns are the most frequent medical emergencies at home. Medical emergencies are causing a burden on healthcare system. Quarter of medical emergencies had negative impact on victim's functional outcome.

\section{References:}

1. Singletary E, Charlton N, Epstein J, Ferguson Jensen J, MacPherson A, et al. Part 15: First Aid;2015 American Heart Association and American Red Cross Guidelines Update for First Aid. Circulation 2015;132: 574-589.

2. National Safe Kids Campaign [online factsheet] (http://www. achd.net/injury/pubs/pdf/KidsSafety_pamphlet.pdf, ac- cessed 9 August 2012).

3. Tomruk $\mathrm{O}$ et al. First aid: level of knowledge of relatives and bystanders in emergency situations. Advances in Therapy, .699-24:691,2007 
4. Goel S, Singh A. Comparative impact of two training packages on awareness and practices of first aid for injuries and common illnesses among high school students in India. International .

5. International federation of red cross and red crescent societies. First aid for a safer future; Updated Global edition, advocacy report 2010. International federation of red cross and red crescent societies.2011.

6. CABRAL E, Castro W, Florintino D, Viana D, Junior J, Souza R, et al. Response time in the emergency services. Systematic review. Acta Cir. Bras. 2018; 33:1110-1121.

7. AlHasan, D, Drennan J , Monger E, et al. Dispatcher assisted cardiopulmonary resuscitation implementation in Kuwait: A before and after study examining the impact on outcomes of out of hospital cardiac arrest victims. Medicine, 98(44);17752.

8. Dagher G, Rajha E, El Khuri C, Bou Chebl R, Mailhac A, Makki M. Epidemiology of burn patients presenting to a tertiary hospital emergency department in Lebanon. Burns. Burns. 2018; 44: 218-225.

9. Khatatbeh M. First Aid Knowledge Among University Students in Jordan. International journal of preventive medicine 2016;7:24.

10. Alomar M, Rouqi F2, Eldali A. Knowledge, attitude, and belief regarding burn first aid among caregivers attending pediatric emergency medicine departments. Burns. 2016;42:938-43.

11. Ministry of Awqaf and Islamic affairs. Quran education centers Summary. Ministry of Awqaf and Islamic affairs,Kuwait.2019.Avilable from URL:< $\mathrm{http} / / /$ douralquran.com/cms/ar/about-us/1/> [accessed on July 6 2019]

12. The public Authority of Civil information. Statistical report. The public Authority of Civil information Kuwait.2019.Avilable from URL: $\underline{\text { http://stat.paci.gov.kw/arabicreports/\#DataTabPlace:ColumnEmpSectorGender }}$ $>$ [accessed on July 6 2019].

13. Segui-Gomez M, MacKenzie E. Measuring the Public Health Impact of Injuries, Epidemiologic Reviews.2003; 25: 3-19.

14. International federation of Red cross and red crescent. First aid for a safer future, focus on Europe. 2009. International federation of red cross and red crescent. Available at: https://www.ifrc.org/PageFiles/53459/First\%20aid\%20for\%20a\%20safer\%20future\% 20Focus\%20on\%20Europe $\% 20 \% 20$ Advocacy\%20report\%202009.pdf?epslanguage= en. [Accessed on August 20, 2019] 
15. Midani O, Tillawi T, Saqer, A, Hammami M, Taifour , \& Mohammad H. Knowledge and attitude toward first aid: A cross-sectional study in the United Arab Emirates. Avicenna journal of medicine.2019; 9(1): 1-7.

16. Van de Velde S, Heselmans A, Roex A, Vandekerckhove P, Ramaekers D, Aertgeerts B. Effectiveness of non-resuscitative first aid training in laypersons: a systematic review. Annals of Emergency Medicine 2009; 54(3):447-457.

17. McDonald E, Mack, K, Shields W, Lee R \& Gielen A.Primary Care Opportunities to Prevent Unintentional Home Injuries: A Focus on Children and Older Adults. American journal of lifestyle medicine. 2016; 12(2): 96-106.

18. O'Hara KA. First aid for seizures: the importance of education and appropriate response. Journal of Child Neurology. 2007;22(5):30-37.

19. Read J, Tan S, Ward L, McDermott K. Burns first aid treatment in remote Northern Australia. Burns.2018: 44(2): 481-487.

20. Lee, H.A., Han, H., Lee, S. et al. The effect of contextual factors on unintentional injury hospitalization: from the Korea National Hospital Discharge Survey. BMC Public Health.2018; 18: 349.

21. Lee, H.A., Han, H., Lee, S. et al. The effect of contextual factors on unintentional injury hospitalization: from the Korea National Hospital Discharge Survey. BMC Public Health.2018; 18: 349.

22. Kool B, Chelimo C, Robinson E, Ameratunga S. Deaths and hospital admissions as a result of home injuries among young and middle-aged New Zealand adults. The Newzeland Medical journal.2011;124:1347 .

\section{Legend section:}

Table 1. Compares between lay people with previous first aid training versus those with no previous first aid training in terms of demographics and impact on management, using Chi square test.

Table 2. Comparison between medical emergencies in terms of burden on health care facilities, Using Chi-square test. 
Table 3. Comparison between medical emergencies in terms of impact on functional outcome, Using Chi-square test.

Figure1. Participants gender during each medical emergency.

Figure 2. Age of victims of home medical emergencies in Kuwait.

Figure 3. Level of compliance with first aid guidelines during the management of each first aid related incident. 
Table 1 Compares between lay people with previous first aid training versus those with no previous first aid training in terms of demographics and impact on management, using Chi square test:

\begin{tabular}{|c|c|c|c|}
\hline Variables & $\begin{array}{c}\text { First-aid Previous training } \\
\qquad \mathrm{N}=194(\%)\end{array}$ & $\begin{array}{l}\text { No First-aid Previous training } \\
\qquad \mathbf{N}=\mathbf{8 2 8}(\%)\end{array}$ & $P$-value $(\mathrm{CI}=95 \%)$ \\
\hline \multicolumn{4}{|l|}{ 1.Gender } \\
\hline a. Male & $91(47)$ & $198(23)$ & $<.001$ \\
\hline b. Female & $103(53)$ & $639(77)$ & \\
\hline \multicolumn{4}{|l|}{ 2. Nationality } \\
\hline a. Kuwaiti & $93(48)$ & $361(43)$ & .29 \\
\hline b. Non-Kuwaiti & $101(52)$ & $467(58)$ & \\
\hline \multicolumn{4}{|l|}{ 3. Background } \\
\hline a. Non-Health related & $96(49)$ & $275(33)$ & \\
\hline b. Health related & $39(20)$ & 23(3) & $<.001$ \\
\hline c. Unemployed & $59(31)$ & $289(64)$ & \\
\hline
\end{tabular}

Cambridge University Press

Disaster Medicine and Public Health Preparedness

\begin{tabular}{|c|c|c|c|}
\hline \multicolumn{4}{|l|}{ 4. Province } \\
\hline a. Al-Asimah & $24(12)$ & $82(10)$ & \\
\hline b. Hawali & $69(35)$ & $428(52)$ & \\
\hline c. Al-Farwanya & $17(9)$ & $71(8)$ & $<.001$ \\
\hline d. Mubarak Al-Kabeer & $12(7)$ & $60(7)$ & \\
\hline e. Al-Ahmidi & $42(22)$ & 98 (12) & \\
\hline f. Al-Jahra & $29(15)$ & $86(11)$ & \\
\hline \multicolumn{4}{|l|}{ 5. Type of management } \\
\hline a. Within $\mathrm{AHA}^{*}$ guidelines & $39(20)$ & $85(11)$ & \\
\hline b. Not within $\mathrm{AHA}^{*}$ guidelines & $21(11)$ & $68(8)$ & \\
\hline c. Called the ambulance & $7(5)$ & $43(6)$ & .001 \\
\hline d. No action & $6(4)$ & $31(5)$ & \\
\hline e. Did not have a first aid incident & $117(60)$ & $594(71)$ & \\
\hline
\end{tabular}




\begin{tabular}{|c|c|c|c|c|c|c|c|c|c|c|c|c|c|c|c|}
\hline $\begin{array}{l}\text { Type of } \\
\text { incident }\end{array}$ & Hypoglycaemia & chocking & $\begin{array}{l}\text { Chest } \\
\text { pain }\end{array}$ & Syncope & Seizures & SOB* $^{*}$ & Wounds & Bleeding & Burn & Anaphylaxis & Stroke & Fracture & Slip/fall & Others & $\begin{array}{l}P \text {-value } \\
(\mathrm{CI}=95 \%)\end{array}$ \\
\hline $\begin{array}{l}\text { Health } \\
\text { care } \\
\text { facility } \\
\text { approach }\end{array}$ & 55 & 8 & 8 & 14 & 21 & 13 & 22 & 12 & 17 & 1 & 4 & 9 & 1 & 3 & $<.001$ \\
\hline $\begin{array}{l}\text { Hospital } \\
\text { admission }\end{array}$ & 29 & 1 & 5 & 6 & 18 & 7 & 3 & 5 & 5 & 0 & 3 & 6 & 0 & 1 & $<.001$ \\
\hline
\end{tabular}

Note: $S O B^{*}=$ Shortness of breath 
Table 3. Comparison between first aid related incidents in terms of impact on functional outcome, Using Chi-square test.

$\mathrm{N}$

\begin{tabular}{|c|c|c|c|c|c|c|c|c|c|c|c|c|c|c|c|}
\hline $\begin{array}{l}\text { Type of } \\
\text { incident }\end{array}$ & Hypoglycaemia & Chocking & $\begin{array}{l}\text { Chest } \\
\text { pain }\end{array}$ & Syncope & Seizures & SOB* & Wounds & Bleeding & Burn & Anaphylaxis & Stroke & Fracture & Slip/fall & Others & $\begin{array}{l}P \text {-value } \\
(\mathrm{CI}=95 \%)\end{array}$ \\
\hline \multicolumn{16}{|c|}{ 1.Functional outcome } \\
\hline $\begin{array}{l}\text { a.Missed } \\
\text { school or } \\
\text { day at } \\
\text { work }\end{array}$ & 18 & 1 & 2 & 3 & 8 & 2 & 4 & 6 & 2 & 0 & 1 & 1 & 0 & 0 & \\
\hline $\begin{array}{l}\text { b.Could } \\
\text { not } \\
\text { practice } \\
\text { daily } \\
\text { activities }\end{array}$ & 21 & 1 & 5 & 5 & 9 & 6 & 7 & 4 & 8 & 1 & 2 & 5 & 1 & 1 & $<.001$ \\
\hline Mortality & 2 & 0 & 0 & 0 & 1 & 0 & 0 & 0 & 0 & 7 & 0 & 0 & 0 & 0 & \\
\hline \multicolumn{16}{|c|}{ 2.Recovery period } \\
\hline $\begin{array}{l}<1 \\
\text { month }\end{array}$ & 30 & 4 & 4 & 7 & 12 & 8 & 24 & 8 & 17 & 1 & 2 & 6 & 2 & 1 & $<.001$ \\
\hline$<1$ year & 6 & 0 & 0 & 0 & 2 & 0 & 0 & 0 & 4 & 0 & 1 & 3 & 0 & 0 & \\
\hline $\begin{array}{l}\text { No } \\
\text { recovery }\end{array}$ & 4 & 0 & 1 & 1 & 4 & 1 & 0 & 0 & 0 & 0 & 1 & 0 & 0 & 0 & \\
\hline
\end{tabular}

Cambridge University Press 
Note: $\mathrm{SOB}^{*}=$ Shortness of Breath 


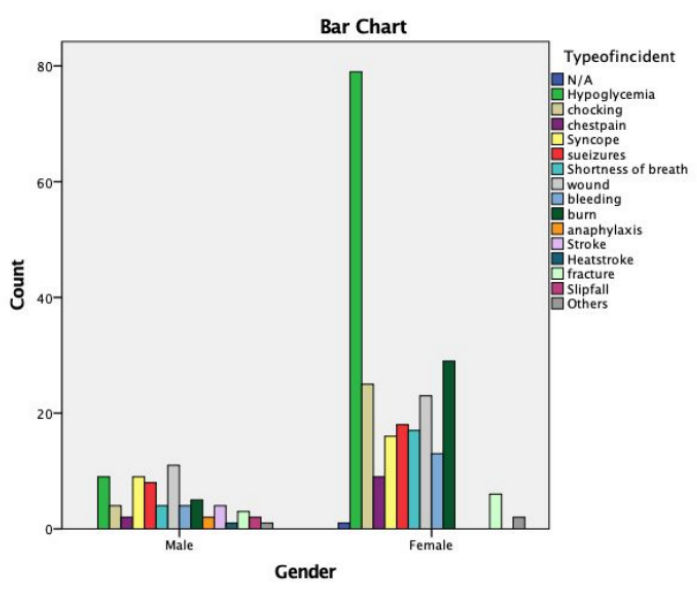

Figure 1. Participants gender during each medical emergency. 


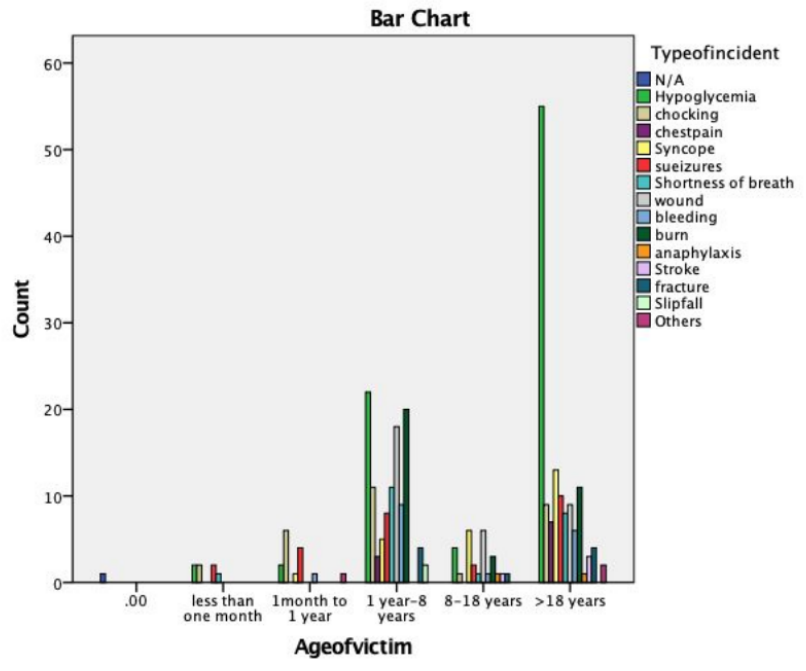

Figure 2. Victims age of medical emergencies at home. 


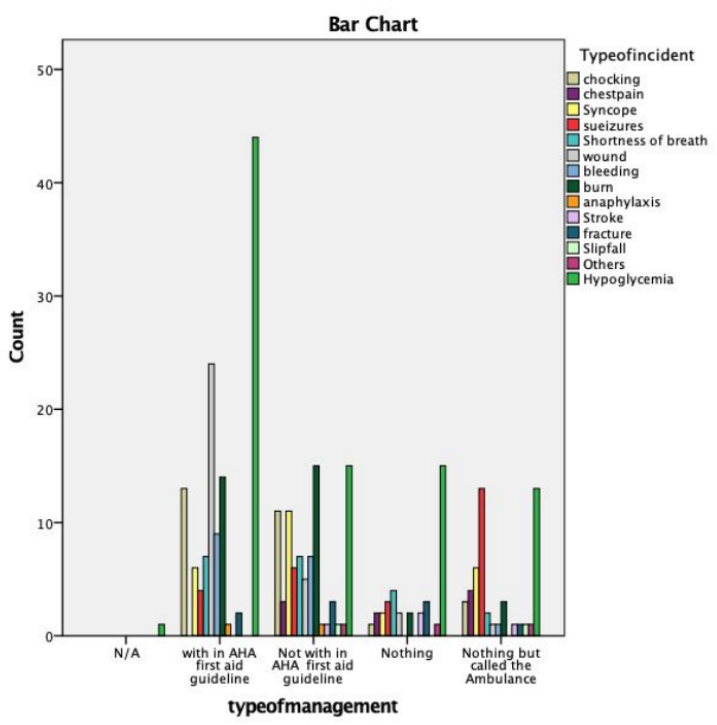

Figure 3. Level of compliance with first aid guidelines during the management of each first aid related incident.

Cambridge University Press 